\title{
Characteristics of sleep disorders in Romanian adults infected with human immunodeficiency virus
}

${ }^{1}$ Medical and Pharmaceutical Research Centre, Medicine and Pharmacy Faculty, "Dunarea de Jos" University from Galati, Romania

${ }^{2}$ Faculty of Medicine, Ovidius University of Constanta, Romania

\begin{abstract}
Sleep disorders commonly occur in chronic diseases and are a great impairment on the quality of life. The current study aims to characterize the sleep problems of a group of Romanian HIV positive patients. A cross sectional study assessed sleep disorders by a series of self-report questionnaires: STOP-BANG, Epworth Sleep Questionnaire and Pittsburgh Sleep Quality Index. Demographic data, antiretroviral therapy, Lymphocytes CD4 levels were collected from medical records. Exclusion criteria were illiteracy, severe neurocognitive dysfunction and depression. We included 102 patients infected with human immunodeficiency virus, age between 22 and 50, sex ratio $\mathrm{M} / \mathrm{F}=1.17$. Reported conditions related to sleep disorders were: smoking (50\%), hypertension (18\%), obesity (6\%) and snoring (7\%). The STOP-BANG scale indicated $19 \%$ intermediate risk and $2 \%$ high risk of sleep apnea. According to Epworth score, daytime sleepiness was found in $18 \%$ of patients, $2 \%$ of them were dangerously sleepy. The average global score of Pittsburg Sleep Questionnaire is indicative of poor sleep quality in $42 \%$ cases. No correlation of sleep scores with antiretroviral regimens was found. Sleep problems with negative impact on daily functioning are frequent
\end{abstract}

Irina Magdalena Dumitru

George Enescu street, no. 23, Constanţa, Romania

email : dumitrui@hotmail.com under age 50 , in patients with human immunodeficiency virus. The management of chronic co-morbidities and psychological support should improve sleep disorders related to human immunodeficiency virus.

Keywords: HIV; sleepiness; sleep apnea; sleep quality.

\section{Introduction}

Sleep is a natural process that maintains the health of our human body. Therefore, sleep disturbances usually influence either the physical or the psychological functioning [1]. Sleep deprivation leads to various effects, such as impaired immune system, hampered physical performance, affected cell growth and repair, deteriorated neuronal connections, neurons malfunctions [2]. The prevalence of sleep disorders in HIV-infected individuals was reported between 40 and $70 \%$ [1]. Sleep disturbances are developing all over the stages of HIV infection, although they are more likely in the advanced of disease $[1,3]$. Lee KA \& all characterized the types of sleep problems on 290 adults with HIV, aged between 22 and 77 years old. They reported 34\% difficulty falling asleep, $56 \%$ fragmented sleep, $45 \%$ less than 6 hours sleep per night and 30\% good sleepers [4]. Regularly, sleep disturbances are associated with depression, fatigue and have a negative influence on antiretroviral therapy adherence in HIV patients $[4,5]$. Consequently, sleep disorders increase the risk 
of developing psychiatric disorders, cardiovascular diseases, healthcare utilization and general mortality [6].

The objective of the present study is to characterize the sleep problems in a group of Romanian HIV positive patients from Galati County.

\section{Material and Methods}

Sleep disorders were assessed in 102 HIV patients attending the regular monitoring medical visit, and in . The age range was 20 to 50 years old. The exclusion criteria were illiteracy, use of illicit drugs, significant neurocognitive dysfunction and severe depression. Screening tests excluded neurocognitive dysfunctions with score of International HIV Dementia Scale less than 8 [7]. Severe depression was considered over 18 score in Beck - II inventory [8]. Following the agreement and the written consent, a number of $102 \mathrm{HIV}$ infected patients self-reported a complex questionnaire series, including STOPBANG Sleep Apnea Questionnaire [9], Epworth Sleepiness Scale [10] and Pittsburgh Sleep Quality Index (PSQI) [11] (Table I). Demographic, clinical, antiretroviral therapy data, current LCD4 count and ARN-HIV levels were collected from medical records. Viral load of HIV was performed by polymerase chain reaction technique and the limit for considering the patient as undetectable was under 400 copies $/ \mathrm{ml}$. The lymphocytes LCD4 level under $500 / \mathrm{mm} 3$ evaluated by flow-cytometric method indicated intermediate or severe immunosuppression
[12]. Categorical variables: gender, marital status, smoking, hypertension, body mass index (BMI), length of HIV diagnostic over 5 years, medication group, CD4 cell count $(>500 ; 200-500 ;<200)$, level of HIV viral load (detectable or undetectable) and drugs based antiretroviral regimens, are presented as frequencies (\%), whereas group differences are analyzed using $\chi 2$ test, with significance level $<0.05$.

Descriptive statistics were used to summarize the sleep scores, according the questionnaire. We analyzed whether there were correlations between immunity, viral load, antiretroviral drugs and apnea risk score, Epworth sleepiness score or Pittsburgh sleep quality index. The significance level $p<0.05$ was considered in the univariate analysis.

\section{Results}

Most patients are young people under age 30, with low education level, unemployed. Over 5 years since HIV diagnostic and stable infection under antiretroviral treatment are prevalent features. Half of patients are smokers, $29 \%$ are overweight or obese and $18 \%$ have hypertension. Owing to antiretroviral treatments, persistent suppression of HIV replication and over $500 / \mathrm{mm} 3$ count of CD4 lymphocytes are gained in most patients. As a peculiarity of Romanian HIV epidemic, many young patients were nosocomially infected during early childhood, accounting for the long time from HIV diagnostic and the high exposure to antiretroviral drugs (Table II).

Table I: Self-administered questionnaires on sleep disorders

\begin{tabular}{llcccc}
\hline Questionnaire & Significance & $\begin{array}{c}\text { No. } \\
\text { items }\end{array}$ & Range & $\begin{array}{c}\text { High } \\
\text { risk }\end{array}$ & $\begin{array}{c}\text { Intermediate } \\
\text { risk }\end{array}$ \\
\hline 1. STOPBANG Sleep Apnea Questionnaire [9] & risk of sleep apnea & 8 & $0-8$ & $5-8$ & $3-4$ \\
\hline 2. Epworth Sleepiness Scale [10] & $\begin{array}{l}\text { general level of } \\
\text { daytime sleepiness }\end{array}$ & 8 & $0-24$ & $>16$ & $>10$ \\
\hline 3. Sleep Quality Index (PSQI) [11] & $\begin{array}{l}\text { quality and patterns } \\
\text { of sleep }\end{array}$ & 9 & $0-21$ & $\geq 5$ & - \\
\hline
\end{tabular}


Table II: Characteristics of HIV patients and correlation with risks of sleep disorders

\begin{tabular}{|c|c|c|c|c|c|c|}
\hline & & \multirow{2}{*}{$\mathrm{N}$} & \multirow{2}{*}{$\%$} & \multicolumn{3}{|c|}{$\mathrm{X}^{2}$ Test (Pearson) } \\
\hline & & & & OSA & Epworth & PSQI \\
\hline \multirow[t]{2}{*}{ Gender } & $\mathrm{F}$ & 47 & $46 \%$ & \multirow{2}{*}{0.983} & \multirow{2}{*}{0.231} & \multirow{2}{*}{0.199} \\
\hline & M & 55 & $54 \%$ & & & \\
\hline \multirow[t]{2}{*}{ Living area } & $\mathrm{U}$ & 57 & $56 \%$ & \multirow{2}{*}{0.779} & \multirow{2}{*}{0.662} & \multirow{2}{*}{0.103} \\
\hline & $\mathrm{R}$ & 45 & $44 \%$ & & & \\
\hline \multirow[t]{3}{*}{ Age (years old) } & $24-29$ & 67 & $66 \%$ & \multirow{3}{*}{$<0.001$} & \multirow{3}{*}{0.477} & \multirow{3}{*}{0.040} \\
\hline & $30-39$ & 23 & $22 \%$ & & & \\
\hline & $40-50$ & 12 & $12 \%$ & & & \\
\hline \multirow{3}{*}{ Education level (years) } & $\leq 8$ & 75 & $73 \%$ & \multirow{3}{*}{0.686} & \multirow{3}{*}{0.992} & \multirow{3}{*}{0.425} \\
\hline & 12 & 15 & $15 \%$ & & & \\
\hline & $>12$ & 12 & $12 \%$ & & & \\
\hline \multirow[t]{2}{*}{ Employed } & Yes & 19 & $19 \%$ & \multirow{2}{*}{0.636} & \multirow{2}{*}{0.813} & \multirow{2}{*}{0.300} \\
\hline & No & 83 & $81 \%$ & & & \\
\hline \multirow[t]{2}{*}{ Couple/married } & Yes & 54 & $53 \%$ & \multirow{2}{*}{0.159} & \multirow{2}{*}{0.806} & \\
\hline & No & 48 & $47 \%$ & & & 0.924 \\
\hline Smoking & Yes & 51 & $50 \%$ & & & \\
\hline & No & 51 & $50 \%$ & 0.536 & 0.603 & 0.316 \\
\hline Nutrition/ & Under weigh & 14 & $14 \%$ & & & \\
\hline Body Mass Index* & Normal & 58 & $57 \%$ & & & \\
\hline$\left(\mathrm{kg} / \mathrm{m}^{2}\right)$ & Overweigh & 24 & $23 \%$ & $<0.001$ & 0.513 & 0.931 \\
\hline & Obesity & 6 & $6 \%$ & & & \\
\hline Hypertension & Yes & 19 & $18 \%$ & $<0 \Omega 01$ & 0665 & 0305 \\
\hline & No & 83 & $82 \%$ & $<0.001$ & 0.665 & 0.305 \\
\hline Length of HIV diagnostic & No & 19 & $19 \%$ & & & \\
\hline$>5$ years & Yes & 83 & $81 \%$ & 0.029 & 0.665 & 0.610 \\
\hline Antiretroviral Treatment & No & 5 & $5 \%$ & & & \\
\hline & Yes & 97 & $95 \%$ & 0.251 & $0.1 / 8$ & 0.920 \\
\hline Drug based regime & & & & & & \\
\hline EFAVIRENZ & Yes & 14 & $14 \%$ & 0.962 & 0.722 & 0.599 \\
\hline RALTEGRAVIR & Yes & 10 & $18 \%$ & 0.663 & 0.504 & 0.412 \\
\hline TENOFOVIR & Yes & 17 & $4 \%$ & 0.519 & 1.000 & 0.928 \\
\hline DARUNAVIR/r & Yes & 2 & $2 \%$ & 0.188 & 0.279 & 0.676 \\
\hline LOPINAVIR/r & Yes & 6 & $6 \%$ & 0.250 & 0.725 & 0.366 \\
\hline $\mathrm{LCD}_{4}\left(/ \mathrm{mm}^{3}\right)$ & $<200$ & 16 & $16 \%$ & & & \\
\hline & $200-500$ & 29 & $28 \%$ & 0.375 & 0.640 & 0.681 \\
\hline & $>500$ & 57 & $56 \%$ & & & \\
\hline ARN-HIV<400c/ml & Yes & 71 & $70 \%$ & 0577 & 0406 & 0641 \\
\hline & No & 31 & $30 \%$ & $0.5 / 1$ & 0.406 & 0.641 \\
\hline
\end{tabular}

*Under weigh<19 kg/m2; Normal: 19-25 kg/m2; Overweigh: 26-30 kg/m2; Obesity>30 kg/m2 
The answers to STOP-BANG Sleep Apnea Questionnaire indicated that $7 \%$ of patients snore loudly, 38\% feel tired, fatigued or sleepy during daytime and $11 \%$ reported that they have stopped breathing during sleep. The median score was $2 \pm 1.23$. Risk stratification scores of sleep apnea indicated that $19 \%$ of patient were at intermediate risk (scores 3-4) and $2 \%$ at high risk (scores 5-8), while the rest of $79 \%$ had low risk (scores $0-2$ ). Medium or high risk of obstructive sleep apnea (OSA) is related to general factors such as age, blood pressure and body weight, while the influence of HIV specific markers, such as LCD4 count and viral load, is not significant.

The average score of Epworth Sleepiness Scale was 5.38 \pm 4.22 . Most likely getting enough sleep are related to $82 \%$ patients with scores under 10 . Evaluation the cause of sleepiness is recommended in $16 \%$ of patients with scores ranged from 10 to 16 , who maybe suffering from excessive daytime sleepiness. Only $2 \%$ patients, with scores over 16 , were identified as dangerously sleepy. Considering that true excessive daytime sleepiness is usually caused by an underlying, undiagnosed, treatable medical condition, these patients require evaluation in a reference sleep center.

The Pittsburgh Sleep Quality Index (PSQI) follows nine items that are grouped in 7 domains [11]. The most significant problems were found in the domains of sleep disturbance $(93.33 \%)$ and daytime dysfunction $(62.75 \%)$, followed by a decrease in subjective sleep quality $(51.96 \%)$, increased sleep latency $(49 \%)$, reduced sleep duration $(48 \%)$ and reduced sleep efficiency (37.2\%). However, no more than $11(10.7 \%)$ patients take sleep medication (Figure 1).

The average global score was $4.64 \pm 2.77$, ranging from 0 to 16 . A total PSQI score over 5 was found in $42 \%$ (43/102) HIV patients, as an indicative of poor sleep quality. As expected, PSQI score is correlated with age (Table II).

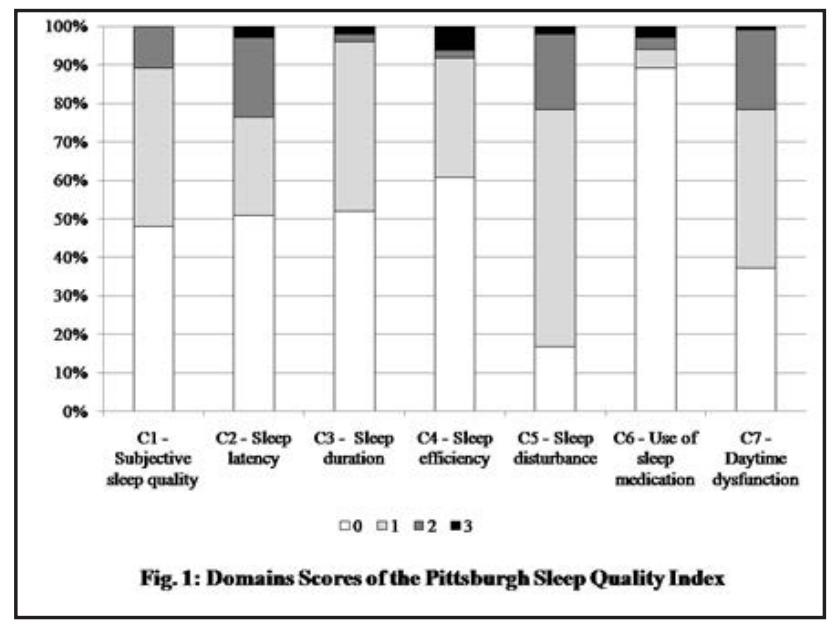

\section{Discussions}

Obstructive sleep apnea (OSA) is defined as "periodic cessation of breathing during sleep and reduced blood oxygen levels", and is accompanied by a high risk of chronic comorbidities, as well as sudden death. The present study found $2 \%$ frequency of severe OSA and 19\% intermediate risk. This is concordant with the estimated $2-4 \%$ prevalence of OSA in the general population [13]. The prevalence of OSA in HIV population is not well documented, although additional risk factors are accepted. Lipodystrophy with fat deposition increases the respiratory effort and can lead to hypoventilation, both day-time and nighttime [13]. Other conditions, such as chronic stress, depression, pain or side effects of opioid medication might exacerbate insomnia [2].

Commonly, worsening sleep is coming with aging [14], concordant with our study. Counting the median age under 30 , we are expecting to escalate the morbidity and mortality related to sleep disorders in our HIV patients, in the next few years.

Sleep architecture in HIV patients was previously characterized: increased sleep latency, increased frequency of nocturnal awakenings, reduced number of hours of sleep, early morning awakening with reversal of the slow wave sleep, particular rapid 
eye movement sleep patterns $[1,15]$. We confirmed increased sleep latency in HIV patients under age 50, according to PSQI.

There are controversial results regarding the association of immune decline during HIV infection and poor sleep quality $[16,17]$ or the influence of HIV on the reduction of slow wave sleep $[15,16,18]$. In our study, there is no correlation between LCD4 count or viral replication and the scores of sleep questionnaires.

Neurological adverse events, including sleep disorders, were previously reported to some antiretroviral drugs, such as non-nucleoside reversetranscriptase inhibitors (Efavirenz, Rilpivirine), protease inhibitors (Atazanavir, Darunavir, Kaletra), integrase inhibitors (Raltegravir, Dolutegravir) or nucleoside reverse-transcriptase inhibitors (Tenofovir) [19]. Increase of sleep latency and decrease of sleep duration are risks within the first weeks of treatment with Efavirenz, usually related to genetic conditions, as the defective CYP2B6 G516T variant allele [20]. In our study, correlation of these drugs based regimens and sleep disorders was not significant (Table II).

\section{Eonclusions}

Nevertheless of stage of HIV infection or antiretroviral regimens, generally features of sleep are poor subjective sleep quality, high sleep latency, poor sleep efficiency, middle risks of dangerous sleepy and of obstructive sleep apnea. Counting the coming age, increasing sleep disorders are expected in the next future. We consider that the best strategy to prevent and control the risks of sleep disorders in the coming years should consider the systematic screening of HIV patients, the control and prevention of hypertension and obesity, the psychological support and pharmacological psychiatric interventions.

\section{Acknowledgments}

The authors express their gratitude to $\mathrm{Dr}$ Sanziana Lovin for the support as expert in sleep problems.

\section{Compliance with ethical standards}

Ethical approval

The study was approved by the local Ethics Committee. Written informed consent was obtained from all patients. All procedures were in accordance with the ethical standards of the institutional research committee and with the international ethical standards.

Conflict of interest

The authors declare no potential conflicts of interest with respect to the research, authorship and/ or publication of this article.

Funding

The authors received no financial support for the research, authorship and/or publication of this article.

\section{References}

1. Oshinaike, O., Akinbami, A., Ojelabi, O., Dada, A., Dosunmu, A. \& John Olabode, S. (2014). Quality of Sleep in an HIV Population on Antiretroviral Therapy at an Urban Tertiary Centre in Lagos, Nigeria. Neurology Research International.2014,6. doi: 10.1155/2014/298703

2. Qaseem, A., Kansagara, D., Forciea, M.A., Cooke, M., \& Denberg, T.D. (2016). Management of Chronic Insomnia Disorder in Adults: A Clinical Practice Guideline From the American College of PhysiciansManagement of Chronic Insomnia 
Disorder in Adults. Annals of internal medicine, 165(2), 125-133.

3. Taibi, D.M. (2013). Sleep disturbances in persons living with HIV. Journal of the Association of Nurses in AIDS Care, 24(1), S72-S85.

4. Lee, K.A., Gay, C., Portillo, C. J., Coggins, T., Davis, H., Pullinger, C.R., \& Aouizerat, B.E. (2012). Types of sleep problems in adults living with HIV/ AIDS. Journal of clinical sleep medicine: JCSM: official publication of the American Academy of Sleep Medicine, 8(1), 67. 67-75.

5. Low, Y., Preud'homme, X., Goforth, H. W., Omonuwa, T., \& Krystal, A. D. (2011). The association of fatigue with depression and insomnia in HIV-seropositive patients: a pilot study. Sleep, 34(12), 1723-1726.

6. Babson, K.A., Heinz, A.J., \& Bonn-Miller, M.O. (2013). HIV medication adherence and HIV symptom severity: the roles of sleep quality and memory. AIDS patient care and STDs, 27(10), 544-552.

7. Sacktor, N., Bacellar, H., Hoover, D., Nance-Sproson, T., Seines, O., Miller, E., Dal Pan, G., Kleeberger, C., Brown, A. \& Saah, A. (1996). Psychomotor slowing in HIV infection: a predictor of dementia, AIDS and death. Journal of neurovirology. 2(6), 404-410.

8. Beck, A.T., Ward, C.H., Mendelson, M., Mock, J., \& Erbaugh, J. (1961). An inventory for measuring depression. Archives of general psychiatry, 4(6), 561571.

9. Chung, F., Yegneswaran, B., Liao, P., Chung, S.A., Vairavanathan, S., Islam, S., Khajehdehi, A. \& Shapiro, C.M. (2008). Stop questionnairea tool to screen patients for obstructive sleep apnea. Anesthesiology: The Journal of the American Society of Anesthesiologists. 108(5), 812-821.

10. Johns, M.W. (1991). A new method for measuring daytime sleepiness: the Epworth sleepiness scale. Sleep. 14(6), 540-545.

11. Buysse, D.J., Reynolds, C.F., Monk, T.H., Berman, S.R., Kupfer, D.J. (1989) The Pittsburgh Sleep Quality Index (PSQI): A new instrument for psychiatric research and practice. Psychiatry Research. 28(2):193-213

12. Selik, R.M., Mokotoff, E.D., Branson, B., Owen, S.M., Whitmore, S., Hall, H.I., Control, C.f.D. \& Prevention. (2014). Revised surveillance case definition for HIV infection-United States, 2014. MMWR Recomm Rep. 63(3), 1-10.

13. Patil, S.P., Schneider, H., Schwartz, A.R. \& Smith, P.L. (2007). Adult obstructive sleep apnea: pathophysiology and diagnosis. Chest. 132(1), 325337.
14. Armstrong, D. \& Dregan, A. (2014). A populationbased investigation into the self-reported reasons for sleep problems. PloS one. 9(7), e101368..

15. Norman, S.E., Resnick, L., Cohn, M.A., Duara, R., Herbst, J. \& Berger, J.R. (1988). Sleep disturbances in HIV-seropositive patients. JAMA. 260(7), 922.

16. Foster, S.B., Lu, M., Glaze, D.G., Reuben, J.M., Harris, L.L., Cohen, E.N., Lee, B.N., Zhao, E., Paul, M.E., Schwarzwald, H., McMullen-Jackson, C., Clark, C., Armstrong, F.D., Brouwers, P.Y., Miller, T.L., Colin, A.A., Scott, G.B., Shahzeidi, S., Willen, E.J., Asthana, D., Lipshultz, S.E., Thompson, B.W. \& Shearer, W.T. (2012). Associations of cytokines, sleep patterns, and neurocognitive function in youth with HIV infection. Clin Immunol. 144(1), 13-23. doi: 10.1016/j.clim.2012.04.004

17. Jean-Louis, G., Weber, K.M., Aouizerat, B.E., Levine, A.M., Maki, P.M., Liu, C., Anastos, K.M., Milam, J., Althoff, K.N. \& Wilson, T.E. (2012). Insomnia symptoms and HIV infection among participants in the Women's Interagency HIV Study. Sleep. 35(1), 131-137.

18. Ferini-Strambi, L., Oldani, A., Tirloni, G., Zucconi, M., Castagna, A., Lazzarin, A. \& Smime, S. (1995). Slow wave sleep and cyclic alternating pattern (CAP) in HIV-infected asymptomatic men. Sleep. 18(6), 446-450.

19. Hoffmann C, Rockstroh JK (2015). HIV 2015/2016. MedizinFokusVerlag, Hamburg

20. Xu, C., Quinney, S.K., Guo, Y., Hall, S.D., Li, L. \& Desta, Z. (2013). CYP2B6 pharmacogenetics-based in vitro-in vivo extrapolation (IVIVE) of efavirenz clearance by PBPK modeling. Drug Metabolism and Disposition, dmd. 113.051755. 